\title{
Transgênicos: avaliação da possível (in)segurança alimentar através da produção científica
}

\author{
Transgenic products: \\ a scientific-production \\ evaluation of possible food \\ (in) security

\begin{abstract}
Maria Clara Coelho Camara
Doutoranda do Programa de Saúde Pública Escola Nacional de Saúde Pública (ENSP) Fundação Oswaldo Cruz (Fiocruz) maria.clara@ensp.fiocruz.br
\end{abstract} \\ Carmem L.C. Marinho \\ Pesquisadora do Centro de Estudos da Saúde \\ do Trabalhador e Ecologia Humana (Cesteh) /ENSP/Fiocruz \\ cmarinho1@oi.com.br

\section{Maria Cristina Rodrigues Guilam} \\ Pesquisadora do Cesteh/ENSP/Fiocruz \\ Rua Leopoldo Bulhões, 1480 - Prédio Primeiro de Maio \\ 21041-210 - Rio de Janeiro - RJ - Brasil \\ guilam@ensp.fiocruz.br

\section{Rubens Onofre Nodari} \\ Professor titular do Centro de Ciências Agrárias \\ Universidade Federal de Santa Catarina \\ Campus Universitário Trindade, caixa-postal 476 \\ 88040-900 - Florianopolis - SC - Brasil \\ rubens.nodari@mma.gov.br
}

Recebido para publicação em maio de 2008. Aprovado para publicação em janeiro de 2009.
CAMARA, Maria Clara Coelho et al. Transgênicos: avaliação da possível (in)segurança alimentar através da produção científica. História, Ciências, Saúde - Manguinhos, Rio de Janeiro, v.16, n.3, jul.-set. 2009, p.669-681.

\section{Resumo}

Identifica e analisa criticamente a produção científica brasileira, no campo da saúde pública, sobre os organismos geneticamente modificados, no que concerne à (in)segurança alimentar. Para tanto, realizou-se uma revisão bibliográfica nos portais do Scientific Eletronic Library Online (SciELO) e da Coordenação de Aperfeiçoamento de Pessoal de Nível Superior (Capes). Dos 716 trabalhos encontrados, apenas oito abordam a segurança alimentar dos transgênicos, através, principalmente, da exposição aos riscos e das incertezas desses produtos para a saúde e o meio ambiente. A principal conclusão do estudo refere-se ao fato de que os oito trabalhos analisados discursam, não sobre a segurança, mas sobre a insegurança dos alimentos geneticamente modificados.

Palavras-chave: transgênicos; segurança alimentar; saúde pública; organismos geneticamente modificados.

\section{Abstract}

Based on a bibliographic review, the article identifies and offers a critical analysis of scientific production by the public health field in Brazil on genetically modified organisms and food (in) security. Of the 716 articles found on the portals of the Scientific Electronic Library Online (SciELO) and the Coordinating Agency for the Development of Higher Education (Capes), only 8 address the food security of transgenic products, primarily in terms of risk exposure and the uncertainties about how these products impact health and the environment. The main conclusion involves the fact that the eight analyzed articles do not speak to the question of the security but rather the insecurity of genetically modified foods.

Keywords: genetically modified products; food safety; public health; genetically modified organisms. 
$\mathrm{O}$ s organismos transgênicos são aqueles cujo genoma foi modificado com o objetivo de atribuir-lhes nova característica ou alterar alguma característica já existente, através da inserção ou eliminação de um ou mais genes por técnicas de engenharia genética (Marinho, 2003). Entre as principais características almejadas encontram-se o aumento do rendimento com melhoria da produtividade e da resistência a pragas, a doenças e a condições ambientais adversas; a melhoria das características agronômicas, permitindo uma melhor adaptação às exigências de mecanização; o aperfeiçoamento da qualidade; a maior adaptabilidade a condições climáticas desfavoráveis e a domesticação de novas espécies, conferindo-lhes utilidade e rentabilidade para o homem (Lacadena, 1998).

A liberação dos transgênicos no Brasil, particularmente aqueles com finalidade comercial, vem provocando intensa polêmica quanto a possíveis riscos à saúde e ao meio ambiente. Tal polêmica, que envolve diversos atores, como cientistas, agricultores, ambientalistas e representantes do governo, refere-se ao nível de incerteza atribuído a esses alimentos diante da chamada 'segurança alimentar' (Marinho, 2003). O conceito surgiu na Europa do século XX, fortemente relacionado à capacidade de os países produzir sua própria alimentação no caso de eventos de guerra e catástrofes. Assim, seu percurso histórico iniciouse associado às noções de soberania e segurança nacional e foi impulsionado pelas consequências da $1^{\text {a }}$ Guerra Mundial, que evidenciou o poder de dominação que poderia representar o controle do fornecimento de alimentos (Maluf, 2007).

Há um intenso conflito entre defensores e críticos da tecnologia transgênica. Grande parte da polêmica emerge da falta de informações completas e confiáveis sobre riscos, benefícios e limitações dessa aplicação. Os vários argumentos, utilizados por ambos os lados da controvérsia, encontram-se no Quadro 1 (Lacey, 2006).

Quadro 1 - Argumentos favoráveis e contrários aos transgênicos

\begin{tabular}{ll}
\hline \multicolumn{1}{c}{ Argumentos favoráveis } & \multicolumn{1}{c}{ Argumentos contrários } \\
\hline Expansão do conhecimento científico. & $\begin{array}{l}\text { Conhecimento incompleto, que desconsidera a } \\
\text { possibilidade de riscos ao ambiente e dos } \\
\text { agrossistemas sustentáveis. }\end{array}$ \\
\hline $\begin{array}{l}\text { Grandes benefícios com o uso imediato dos } \\
\text { transgênicos (sementes com qualidade nutritiva }\end{array}$ & $\begin{array}{l}\text { Benefícios medíocres, limitados ao grupo de grande } \\
\text { produtores, sem alcançar o pequeno produtor; seu } \\
\text { desenvolvimento reflete interesses do sistema de } \\
\text { mercado global. }\end{array}$ \\
\hline $\begin{array}{l}\text { Ausência de perigos para a saúde humana e } \\
\text { ambiental que se originem de seu uso e que não }\end{array}$ & $\begin{array}{l}\text { Os maiores riscos podem não ser os que afetam } \\
\text { diretamente a saúde humana e o ambiente, mas sim } \\
\text { possam ser adequadamente administrados por }\end{array}$ \\
regulamentações planejadas. & $\begin{array}{l}\text { aques ocasionados pelo contexto socioeconômico da } \\
\text { pesquisa e do desenvolvimento de transgênicos e de }\end{array}$ \\
seus mecanismos associados, tais como a estipulação \\
que as sementes transgênicas são objetos em relação \\
aos quais os direitos de propriedade intelectual devem \\
ser garantidos.
\end{tabular}

Inexistência de formas alternativas de agricultura a serem desenvolvidas em seu lugar, sem ocasionar riscos inaceitáveis (ex.: falta de alimento).
Encontram-se em desenvolvimento métodos agroecológicos que permitem alta produtividade em lavouras essenciais e ocasionam riscos relativamente menores; promovem agrossistemas sustentáveis; utilizam e protegem a biodiversidade; e contribuem para a emancipação social das comunidades pobres. 
Segundo Valle (2000) e Cavalli (2001), a intensa controvérsia que cerca o tema não possibilitou ainda uma definição clara quanto à segurança dos transgênicos para o consumo. A falta de conhecimento científico sobre os riscos é um fator associado à situação acima referida. Com base nisso, este estudo tem como proposta identificar e analisar criticamente a produção científica brasileira, no campo da saúde pública, sobre os organismos geneticamente modificados (OGMs), no que concerne à identificação da possível (in)segurança alimentar.

\section{Caminho metodológico}

Para realizar a análise aqui proposta, realizou-se uma revisão bibliográfica nos portais do Scientific Eletronic Library Online (http://www.scielo.org/), rede de divulgação da comunicação científica nos países do Caribe e da América Latina, e da Coordenação de Aperfeiçoamento de Pessoal de Nível Superior (Capes), instituição responsável pela pósgraduação stricto sensu no Brasil. Tem-se como pressuposto que a seleção nesses portais configura amostra representativa de como o tema vem sendo tratado no campo da saúde pública no Brasil. Cabe destacar que, na seleção realizada no portal SciELO, considerou-se a disponibilidade integral dos artigos, para viabilizar discussão mais aprofundada e detalhada do material. Considera-se que os estudos selecionados justificam-se por sua legitimidade, uma vez que representam pesquisas, comprovam pressupostos e são obrigatoriamente submetidos à avaliação por pares.

Os descritores utilizados para recuperar, nos portais da SciELO e da Capes, os estudos foram transgênico(s); OGM(s); transgênicos e segurança alimentar; OGMs e segurança alimentar; transgênicos e saúde pública. Através desses descritores foi possível adquirir uma visão ampla sobre como os transgênicos vêm sendo tratados no campo da saúde pública.

\section{Análise dos resultados}

A busca por intermédio dos descritores mencionados resultou na localização de 716 estudos, dos quais 80 eram artigos e 636, teses e dissertações. O período da pesquisa foi de 1987 a 2008, e verificou-se que a maior parte das publicações ocorreu a partir de 1998 (aproximadamente 95\%), em especial em 2007, ano que compreendeu 13,2\% das publicações (94 estudos).

A literatura científica sobre transgênicos é ampla e diversa. Tange assuntos como rotulagem, direito do consumidor, biossegurança, experimentos em laboratórios, produção, comercialização e liberação comercial, riscos e benefícios oriundos dessa tecnologia. Apesar do grande número de referências reunidas sobre o tema, apenas oito estudos abordam especificamente a (in)segurança alimentar dos alimentos geneticamente modificados. Um resumo desses estudos encontra-se no Quadro 2.

Estudo semelhante ao exposto neste artigo foi realizado por Domingo (2007), que fez uma revisão da literatura no portal Medline. Nela foram identificadas mais de cinco mil referências a transgênicos, entretanto quanto à avaliação de risco - objetivo principal - 
localizaram-se apenas 29 escritos. O autor conclui que a tecnologia transgênica é nova e que os cientistas ainda não têm um conhecimento completo sobre ela. Afirma ainda que são necessários mais estudos científicos e investigações para garantir que a ingestão de alimentos geneticamente modificados não apresenta riscos para a saúde da população e o meio ambiente.

Quadro 2 - Artigos e teses/dissertações sobre segurança alimentar de produtos GM

\begin{tabular}{|c|c|c|c|}
\hline Título & Autor(es) & $\begin{array}{c}\text { Tipo de } \\
\text { publicação }\end{array}$ & Objetivo \\
\hline $\begin{array}{l}\text { Segurança alimentar de milho } \\
\text { geneticamente modificado, } \\
\text { contendo o gene } \\
\text { CryAb de Bacillus } \\
\text { thuringiensis }\end{array}$ & Venzke, J.G. & Dissertação & $\begin{array}{l}\text { Avaliar a toxicidade subcrônica } \\
\text { do milho Bt em camundongos da } \\
\text { linhagem BALB/c. }\end{array}$ \\
\hline $\begin{array}{l}\text { Organismos modificados } \\
\text { genéticamente: una nueva } \\
\text { amenaza para la } \\
\text { seguridad alimentaria }\end{array}$ & Spendeler, L. & Artigo & $\begin{array}{l}\text { Analisar todos os aspectos referentes à } \\
\text { segurança alimentar relacionados com } \\
\text { a introdução dos OGMs na agricultura } \\
\text { e na alimentação. }\end{array}$ \\
\hline $\begin{array}{l}\text { Pensando sobre el riesgo } \\
\text { alimentario y su } \\
\text { aceptabilidad: el caso de los } \\
\text { alimentos transgénicos }\end{array}$ & Arnaiz, M.G. & Artigo & $\begin{array}{l}\text { Analisar a percepção social da } \\
\text { segurança alimentar e, em particular, } \\
\text { as representações sociais do risco } \\
\text { oriundo dos OGMs. }\end{array}$ \\
\hline $\begin{array}{l}\text { Plantas transgênicas e seus } \\
\text { produtos: impactos, riscos } \\
\text { e segurança alimentar } \\
\text { (biossegurança de plantas } \\
\text { transgênicas) }\end{array}$ & $\begin{array}{l}\text { Nodari, R.O.; } \\
\text { Guerra, M.P. }\end{array}$ & Artigo & $\begin{array}{l}\text { Analisar os riscos oriundos dos } \\
\text { transgênicos, destacando a aplicação } \\
\text { do conceito de equivalência } \\
\text { substancial como critério de avaliação } \\
\text { de segurança alimentar dos OGMs. }\end{array}$ \\
\hline $\begin{array}{l}\text { Segurança alimentar: a } \\
\text { abordagem dos } \\
\text { alimentos transgênicos }\end{array}$ & Cavalli, S.B. & Artigo & $\begin{array}{l}\text { Discutir a relação entre a segurança } \\
\text { alimentar e os alimentos } \\
\text { geneticamente modificados. }\end{array}$ \\
\hline $\begin{array}{l}\text { Transgênicos sem } \\
\text { maniqueísmo }\end{array}$ & Valle, S. & Artigo & $\begin{array}{l}\text { Analisar incertezas e riscos da } \\
\text { tecnologia, principalmente com } \\
\text { relação à posição ambígua das } \\
\text { multinacionais. }\end{array}$ \\
\hline A voz dos cientistas críticos & Lewgoy, F. & Artigo & $\begin{array}{l}\text { Discutir as controvérsias sobre os } \\
\text { transgênicos, enfatizando riscos, } \\
\text { incertezas e exemplos de falhas dessa } \\
\text { tecnologia. }\end{array}$ \\
\hline $\begin{array}{l}\text { Investigating the } \\
\text { environmental risks } \\
\text { of transgenics crops } \\
\text { de }\end{array}$ & Lacey, H. & Artigo & $\begin{array}{l}\text { Discutir os tipos de investigação } \\
\text { científica necessários para um exame } \\
\text { adequado da inexistência de riscos e } \\
\text { alternativas melhores aos } \\
\text { transgênicos. }\end{array}$ \\
\hline
\end{tabular}

A análise da produção científica relativa à (in)segurança alimentar dos transgênicos revela dois critérios centrais e antagônicos a nortear os argumentos favoráveis e os contrários à liberação e comercialização dos alimentos geneticamente modificados. O primeiro referese ao critério da 'equivalência substancial' (ES), segundo o qual o organismo geneticamente modificado, sendo similar a sua contraparte convencional, é considerado substancialmente equivalente, inexistindo, portanto, razões para considerá-lo perigoso. Tal critério vem sendo utilizado por autoridades regulatórias globais (FAO, 2000) e por Estados Unidos, Canadá e 
Argentina. Na União Europeia, a ES é um dos componentes da análise de risco, tomandose como ponto de partida a diretiva 2001/18/CE (Parlamento Europeu, 17 abr. 2001), embora o referido critério tenha sempre recebido críticas por parte da comunidade científica (Millstone, Brunner, Mayer, 1999).

O segundo critério refere-se ao 'princípio da precaução' (PP) que surgiu como uma ferramenta a ser utilizada quando for impossível efetuar a avaliação científica do risco, servindo para impedir ações que possam causar danos ambientais (Freestone, Hey, 1996). Adotado pela Convenção Sobre Diversidade Biológica (CDB), o PP preconiza essencialmente que, em caso de ameaça de redução ou perda de diversidade biológica, a simples falta de plena certeza científica não deve ser usada para postergar medidas que evitem ou minimizem essa ameaça (Brasil, s.d.) Assim, a adoção do princípio constitui uma alternativa a ser adotada diante de incertezas científicas.

Para muitos autores, o PP se adequa perfeitamente aos OGMs e, portanto, deveria ter sido empregada desde os primórdios da tecnologia. Marinho (2003) argumenta que o princípio teria beneficiado inclusive o desenvolvimento dessa tecnologia, já que por certo ela sofreria menor questionamento e rejeição, em especial pela sociedade civil organizada. Não é possível - ainda - avaliar os impactos mensuráveis dos transgênicos na saúde humana, com base em indicadores como mortalidade infantil ou expectativa de vida (Ruttan, 1999). É indispensável, no entanto, considerar o nível de incerteza no que diz respeito às implicações dessa tecnologia, uma vez que, segundo Caruzo (2006), as incertezas cientificas, mais do que as certezas cientificas, estão associadas aos riscos. Em síntese, na discussão sobre os alimentos transgênicos a equivalência substancial se contrapõe ao princípio da precaução, pois enquanto a primeira evita a identificação de riscos e não leva em conta as incertezas científicas, o segundo preconiza essencialmente o contrário.

A avaliação dos alimentos produzidos pela engenharia genética requer, por sua complexidade, uma abordagem holística (Traavik, Ching, 2007). Os testes usuais de toxicidade parecem carecer de um rigor particular (FAO, 2000). Millstone, Brunner e Mayer (1999) observam: demonstrar que um alimento geneticamente modificado é quimicamente similar a sua contraparte natural não constitui prova suficiente de segurança para o consumo humano. O conceito de ES, considerado pseudocientífico pelos autores, teria sido adotado com objetivos políticos e comerciais condizentes com os interesses das empresas produtoras dos OGMs, desejosas de tranquilizar os consumidores.

A adoção do critério da ES pressupõe também ignorar os mecanismos de segregação e preservação da identidade, uma vez que, sob essa ótica, tanto os alimentos naturais seriam iguais aos geneticamente modificados. Em 2000, a descoberta de um produto contaminado com uma variedade de milho Bt da Aventis nos EUA - que não havia sido aprovada para consumo humano - colocou a indústria biotecnológica na defensiva (Tokar, 2001). Os consumidores perceberam que estavam expostos a um risco fora de seu controle, e evidenciouse a importância de estabelecer mecanismos de segregação entre colheitas geneticamente modificadas e não modificadas. Uma das medidas tomadas foi a rotulagem dos alimentos.

No Brasil, em meio a tal cenário de incertezas, cabe à Comissão Técnica Nacional de Biossegurança (CTNBio) avaliar, caso a caso, os possíveis riscos oferecidos pelos transgênicos cuja liberação vem sendo requerida, para fins experimentais ou comerciais. A Comissão 
teve sua competência e composição estabelecida pelo decreto 1.752, que regulamentou a lei 8.974, ambos de 1995. A lei foi contestada pela Justiça e obrigou o poder executivo a baixar a medida provisória 2.191/9, de 2001. Desde março de 2005 a biossegurança está sob a égide de uma nova legislação, a lei 11.105, mas a instrução normativa 20, de 11 de dezembro de 2001, que dispõe sobre as normas para avaliação da segurança alimentar de plantas geneticamente modificadas ou de suas partes, foi elaborada sob a lei anterior, portanto revogada (Brasil, 21 dez. 1995, 16 jan. 1995, 24 ago. 2001, 28 mar. 2005, 17 jan. 2002). De todo modo, a instrução normativa é instrumento privilegiado para estudos de avaliação dos alimentos transgênicos quanto à sua segurança para o consumo.

\section{Insegurança alimentar dos transgênicos}

Nos oito estudos que abordam a segurança alimentar dos alimentos transgênicos, a análise é feita principalmente pela exposição de riscos e incertezas desses produtos, quanto a saúde e meio ambiente. O termo segurança alimentar e nutricional foi definido em 2004, por ocasião da $2^{a}$ Conferência Nacional de Segurança Alimentar e Nutricional, como: “a realização do direito de todos ao acesso regular e permanente a alimentos de qualidade, em quantidade suficiente, sem comprometer o acesso a outras necessidades essenciais, tendo como base práticas alimentares promotoras de saúde, que respeitem a diversidade cultural e que sejam social, econômica e ambientalmente sustentáveis" (Menezes, Burlandy, Maluf, 2004, p.14). Trata-se de um conceito abrangente, que, no Brasil, engloba os termos food safety (alimento seguro) e food security (segurança alimentar).

Os Ministérios da Saúde e da Agricultura, Pecuária e Abastecimento são os órgãos responsáveis pelo controle da qualidade de toda a cadeia alimentar. Cabe destacar, no entanto, que a política de fiscalização desempenhada por esses órgãos é precária e convive, ainda, com a fome e a miséria de grande parte da população.

A Codex Alimentarius Commision, da Organização das Nações Unidas para Agricultura e Alimentação (FAO) adotou, em 2003, uma lista de princípios para a análise dos riscos oriundos da aplicação da técnica de transgenia. Além disso, descreve, também, uma metodologia para conduzir as avaliações da segurança alimentar desses produtos (WHO, 2005). Os princípios de avaliação requerem a investigação de: (a) efeitos diretos para a saúde (toxicidade); (b) tendência a provocar reações alérgicas (alergenicidade); (c) componentes específicos que promovem propriedades nutricionais ou tóxicas; (d) estabilidade do gene inserido; (e) efeitos nutricionais associados com a modificação genética específica; e (f) qualquer efeito não intencional que pode resultar da inserção genética.

Cavalli (2001) ressalta outro aspecto quanto ao risco da aplicação da engenharia genética: o argumento de que os OGMs poderiam solucionar o problema da fome no mundo. Tal afirmação teria levado as indústrias de biotecnologias a realizar uma "nova revolução verde", objetivando, com isso, o aumento da produção de alimentos para acabar com o problema da fome. Ressalta-se, entretanto, que o aumento da produção de alimentos não possibilitará a segurança alimentar e nutricional, uma vez que tal problema não decorre da produção de alimentos, mas sim de sua distribuição para a população. 
Além disso, a monopolização das sementes transgênicas pode proporcionar a diminuição da disponibilidade de alimentos, como destaca Spendeler (2005) ao analisar a segurança alimentar dos produtos transgênicos, discutindo as incertezas, os riscos e a monopolização desses alimentos. Segundo a autora, todas as sementes transgênicas pertencem a um pequeno número de multinacionais, daí resultando a monopolização do mercado mundial desementes, com os agricultores cada vez mais dependentes dessas empresas. A autora afirma: "a segurança alimentar em termos de disponibilidade de alimentos está em jogo" (p.279; tradução livre). Apresenta, ainda, as incertezas da engenharia genética, como a alta probabilidade de efeitos imprevistos e indesejáveis. Spendeler conclui seu estudo ressaltando a pequena quantidade de estudos sobre o assunto e a tendência à industrialização que tais cultivos proporcionam, desconsiderando as necessidades das comunidades locais e a biodiversidade agrícola. Tais aspectos constituem fatores importantes para atestar a insegurança alimentar desses produtos.

É importante considerar a percepção da população em relação aos OGMs. Arnaiz (2004) analisou algumas pesquisas de opinião sobre transgênicos e concluiu que, com o avanço do consumo desses alimentos, ocorreu também um aumento da percepção negativa dos indivíduos a respeito das novas aplicações tecnológicas na alimentação. Afirma, ainda, sabermos pouco sobre o que comemos, e que as incertezas da população a respeito dos OGMs deriva do comportamento das instituições responsáveis pela avaliação dos riscos desses alimentos.

Sobre as instituições, Lacey (2004) verifica que as políticas públicas que apoiam o cultivo de transgênicos consideram não haver alternativas nem riscos na aplicação da transgenia. Essa postura política, no entanto, ignora as práticas agroecológicas e o princípio da precaução, além de expor a população a riscos ainda não mensuráveis.

As incertezas sobre os transgênicos também estão presentes nas empresas detentoras dessa tecnologia, uma vez que apresentam argumentos contraditórios e de acordo com seus interesses: ao mesmo tempo que argumentam sobre a segurança alimentar de seus produtos (com base no conceito ES), consideram-nos diferentes dos naturais no que concerne à propriedade intelectual (Valle, 2000).

No cenário atual de incertezas sobre os possíveis efeitos dos alimentos transgênicos, a rotulagem é um mecanismo que possibilita ao consumidor decidir se aceita ou não consumir alimentos cujas propriedades não são ainda suficientemente conhecidas pela ciência. Além disso, é direito do consumidor ser informado de maneira adequada sobre a qualidade, quantidade e composição dos alimentos que pretende adquirir. A rotulagem permite, ainda, rastrear a origem do alimento, em casos de eventuais problemas. A questão da rotulagem precisa ser compreendida no âmbito da segurança alimentar. Sem rotulagem, é impossível fazer biovigilância.

O estudo de Cavalli (2001) apresenta uma controvérsia sobre a biotecnologia e a biossegurança: a primeira é compreendida como um campo que colocará o Brasil em condições de competir com as demais nações desenvolvidas, e a segunda é encarada como o freio para a produção de transgênicos sem análises profundas e de longo prazo acerca dos riscos para a saúde e o meio ambiente. Nodari e Guerra (2003) corroboram com a 
autora e destacam a importância da rotulagem como um instrumento fundamental dos indivíduos na escolha desses alimentos.

Outros aspectos também contemplados pelo campo da segurança alimentar são o impacto na exportação de alimentos, e mesmo no turismo, para os países produtores, sobretudo numa economia globalizada. Eventos recentes como o conhecido mal da vaca louca, na Inglaterra, e o acidente da dioxina, na cadeia de alimentação humana, na Bélgica, são capazes de abalar fortemente a credibilidade dos consumidores (Borges, 2000). Tais eventos repercutiram na credibilidade dos OGMs e, provavelmente, contribuíram para que o avanço da biotecnologia agrícola tenha sido mais lento do que fora anunciado no começo dos anos 1980 (Ruttan, 1999). Em grande medida e a despeito das prováveis dificuldades da técnica em si, a reação dos consumidores representou e representa um entrave considerável.

Outras preocupações relacionadas com os OGMs são o receio de uma possível resistência bacteriana aos antibióticos empregados na modificação genética, e o aumento das alergias alimentares às novas proteínas (Nodari, Guerra, 2003). Utilizam-se genes marcadores de resistência a antibióticos, cuja função é selecionar e confirmar se a alteração genética foi de fato realizada da maneira planejada. No entanto, discute-se que tais genes podem continuar a ser expressos nos tecidos da planta e, ao serem ingeridos através dos alimentos, reduziriam, no homem, a eficácia do antibiótico comumente administrado no combate a doenças. Argumenta-se também que esses genes de resistência poderiam ser transferidos a patógenos humanos ou animais, tornando nulo o efeito da aplicação de certos antibióticos. A crescente resistência de organismos aos antibióticos vem sendo avaliada como problema grave para a saúde pública (Union of Concerned Scientists, 2001). Nos EUA, o Food and Drug Administration (FDA, 4 set. 1998) parece reconhecer tal possibilidade quando, em relatório de grupo consultivo reunido com o objetivo de avaliar a questão, recomenda como regra a adoção de cuidados no uso dos antibióticos.

A Organização Mundial de Saúde (OMS) e associações médicas americanas, entre outros, expressam preocupação de que se "os genes resistentes a antibióticos" usados em alimentos GM se transferissem para bactérias, poderiam resultar no aparecimento de superdoenças. Tal fato motivou a Associação Médica Britânica a declarar uma moratória para alimentos GM (Jeffrey, 2004).

Com relação aos riscos para o meio ambiente, destacam-se as transferências vertical (acasalamento sexual entre indivíduos da mesma espécie) e horizontal (DNA transferido de uma espécie para outra, aparentada ou não). No Brasil, região de grande variedade genética de sementes crioulas, esse tipo de risco configura grande desafio (Nodari, Guerra, 2003). Lewgoy (2000), por sua vez, analisou os riscos ambientais dos alimentos transgênicos e apontou a possibilidade de cruzamentos genéticos não esperados. Destaca falhas nos testes de toxicidade apresentados por uma empresa produtora de transgênicos à CTNBio e a falta de avaliação adequada dos riscos de toxicidade e alergias de seu produto, para obtenção da liberação comercial.

Com relação à liberação comercial, Marinho e Minayo-Gomez (2004) analisaram o tratamento dado pela CTNBio a solicitações de liberações ambientais de transgênicos. Os autores concluíram que, apesar do amplo arcabouço legal existente, as instâncias 
governamentais não conseguiram assegurar o cumprimento da biossegurança, "adotando uma postura negligente no estabelecimento das exigências técnicas legais" (p.101).

No Portal de Periódicos da Capes, observou-se apenas uma dissertação que aborda a (in)segurança alimentar dos transgênicos (Venzke, 2006). Elaborada no formato de três artigos, a tese tem como primeira parte uma revisão bibliográfica sobre a instrução normativa 20 de 2001 (mencionada anteriormente) e aponta a necessidade de estudos aprofundados sobre ela em que se priorize a análise de toxicidade e alergenicidade.

A alergenicidade é um importante risco a ser analisado, considerando-se que os alergênicos alimentares são proteínas que podem ser oriundas de genes endógenos ou exógenos. Com o objetivo de avaliar o potencial de alergenicidade de proteínas transgênicas, a FAO estabeleceu inicialmente a comparação das estruturas da nova proteína com as de alergênicos já conhecidos, alinhando as sequências de aminoácidos em bases de dados. A seguir, caso a fonte do gene fosse confirmada como alergênica, deveria ser realizado um teste com soro de pacientes alérgicos a essa fonte. A dissertação em questão alerta para a necessidade de atenção particular ao possível potencial alergênico do milho Bt (Venzke, 2006).

$\mathrm{Na}$ avaliação pelo critério da ES, o óleo de milho transgênico, por exemplo, não precisaria ser rotulado como geneticamente modificado, porque seu processo de produção seria capaz de separar todos os constituintes tóxicos do milho, e a composição final seria idêntica àquela obtida do milho não-alterado geneticamente. Argumentos similares têm sido usados para fundamentar a desregulamentação do óleo de soja geneticamente modificado. Segundo Fagan (2002), há dois problemas com tal argumentação: primeiro, o óleo de milho não é quimicamente puro e contém proteínas suficientes do milho para provocar reações alérgicas nos indivíduos sensíveis; segundo, na avaliação do óleo de milho geneticamente modificado pela estratégia da ES, somente os principais constituintes são examinados, e os demais, ignorados nessa avaliação, podem ter papel importante no valor nutricional ou na própria segurança do produto. Como exemplo, as manipulações genéticas podem inesperadamente, por meio de determinados mecanismos, alterar o metabolismo do óleo e gerar um derivado tóxico de ácido graxo. Conclui a autora que o critério de ES é superficial e não pode ser utilizado como argumento para justificar a não realização de testes e/ou rotulagem.

O segundo artigo da referida dissertação aborda a relação dose/resposta de camundongos alimentados, por noventa dias, com diferentes concentrações de milho Bt e com a proteína Cry1Ab. Foram preparados quatro tipos de dietas: a controle (sem milho Bt), a com Cry1 Ab e aquelas em que foram acrescidos 10\% a 30\% de milho Bt. Concluiu-se que os camundongos que consumiram milho transgênico tiveram ganho de peso e menor comportamento animal (erguer, brincar e festejar). Ressalte-se que a alteração genética no milho Bt é a inserção de um gene oriundo da bactéria do solo Bacillus thuringiensis. As toxinas desse bacilo são eficazes (mortais) contra diversas variedades de insetos que atacam plantações como as de milho e algodão. Com a transgênese, o gene recebido pela planta codifica uma das toxinas Bt e impede que a planta seja danificada pelos insetos, enquanto não houver insetos resistentes à referida toxina. Ou seja, a própria planta exerce função inseticida matando os insetos que dela se alimentam (Marinho, 2003).

A avaliação da segurança alimentar do milho Bt foi concluída no terceiro artigo, no qual, com base no experimento mencionado, a autora observou que os camundongos 
alimentados com o milho acrescido da proteína Cry1Ab apresentaram degeneração, necrose e aumento do volume do fígado.

Em 1999 um estudo elaborado por Losey, Rayor e Carter (1999) comprovou resultados semelhantes e causou, à época, grande impacto junto à comunidade científica. O estudo comparou o desenvolvimento de larvas alimentadas com folhas em que o pólen do Bt havia sido aspergido, com outras alimentadas com folhas sem o pólen do milho Bt. Concluiu que as larvas do primeiro grupo comeram menos, cresceram mais lentamente e apresentaram maior taxa de mortalidade.

Outro estudo de grande importância, cujos resultados foram publicados na revista científica The Lancet e provocaram intensa polêmica, foi realizado pelo cientista Arpad Pusztai, no Rowett Institute da Escócia, utilizando ratos alimentados com batatas transgênicas. Concluiu que os animais apresentavam alterações no sistema imunológico e no desenvolvimento de órgãos vitais. Pusztai destacou que as alterações poderiam ser causadas pela expressão do gene utilizado na modificação das batatas, como também devido à presença, no vetor, de um ou mais genes usados na transferência gênica, ou, ainda, em virtude de distúrbios no funcionamento dos próprios genes da batata, em consequência da incorporação aleatória do vetor no seu genoma. Tais conclusões foram questionadas pela The Royal Society, baseada em estudos semelhantes que não chegaram aos mesmos resultados, sugerindo que o cientista precisaria refinar seu projeto experimental e realizar estudos adicionais, definindo claramente as hipóteses focalizadas nos efeitos específicos relatados. A despeito da necessidade de mais estudos na linha de investigação desenvolvida por Pusztai, a pesquisa distingue-se por ter sido realizada sem financiamento de empresas, ao contrário de grande parte dos trabalhos sobre o assunto (Pusztai, 2002).

A principal conclusão dessa dissertação foi a insegurança alimentar do milho transgêncico Cry $1 \mathrm{Ab}$. As demais teses e dissertações encontradas no portal abordam questões como legalização dos OGMs (Salles, 2006; Carvalho, 2003), rotulagem (Cavalcanti, 2006; Costabile e Solimene, 2004), repercussões econômicas, institucionais e políticas (Carmo, 2006; Souza, 2006; Pizzatto, 2006; Franco, 2006; Sousa, 2001), resistências genéticas (Pinto, 2002) e biossegurança (Paz, 2004).

\section{Considerações e recomendações finais}

A principal conclusão refere-se à pequena produção científica sobre a segurança alimentar dos OGMs no campo da saúde pública, quando comparada aos demais estudos sobre os transgênicos. O escasso número de estudos sobre o tema evidencia que a polêmica sobre a adoção/incorporação desses alimentos justifica-se, entre outros elementos mencionados anteriormente, pela incerteza de seus efeitos sobre a saúde e o meio ambiente, como também pela ausência de dados experimentais.

Outra conclusão refere-se ao fato de todos os estudos discursarem sobre a insegurança alimentar dos alimentos geneticamente modificados, o que permite apontar uma questão importante: que estudos embasaram a CTNBio na permissão para as liberações comerciais de transgênicos, se na amostra por nós analisada todos afirmam que tais alimentos não são seguros? 
Recomenda-se também a avaliação da eficácia da instrução normativa 20, proposta pela CTNBio, principal instrumento para analisar a segurança alimentar dos transgênicos no Brasil, mesmo que esse principal instrumento para analisar a segurança alimentar dos transgênicos no Brasil tenha sido revogado. Em seu lugar, surge a resolução normativa 5, de 12 de março de 2008, que dispõe sobre normas para liberação comercial de OGMs e derivados, em que a análise de questões relativas à qualidade nutricional (modificação e/ ou inserção de novos carboidratos ou gorduras), à alergenicidade e aos efeitos adversos à saúde oriundos dos transgênicos fica em segundo plano.

Contudo, o mais intrigante é a aprovação de três tipos de milho transgênico, o milho Liberty Link (evento LL25), o milho Guardian (evento MON810) e o milho Bt11 (evento Bt11), sem estudos sobre segurança alimentar e riscos ao meio ambiente nos ecossistemas brasileiros, contrariando as normas mais elementares de biossegurança, razão pela qual o IBMA e a Agência Nacional de Vigilância Sanitária (Anvisa) recorreram contra a decisão da CTNBio, junto ao Conselho Nacional de Biossegurança.

\section{REFERÊNCIAS}

ARNIZ, Mabel Gracia.

Pensando sobre el riesgo alimentario y su aceptabilidad: el caso de los alimentos transgénicos. Revista de Nutrição, Campinas, v;17, n.2, p.125-49. 2004.

BORGES, Miguel.

A segurança alimentar e a sustentabilidade do agroecossistema. Rumos \& Debates, Brasília. Disponível em: http://www23.sede.embrapa.br: 8080/aplic/rumos.nsf/b1bbbc852ee1057183256 $800005 \mathrm{ca0ab} /$ ccec784ccf50bd3583256904005 48791?OpenDocument. Acesso em: 24 jun. 2008. 2000.

BRASIL.

Comissão Técnica Nacional de Biossegurança. Lei 11.105 de 24 de março de 2005. Dispõe sobre as normas de segurança e mecanismos de fiscalização de atividades que envolvam organismos geneticamente modificados - OGM e dá outras providências. Diário Oficial da União, Brasília. 28 mar. 2005.

BRASIL.

Comissão Técnica Nacional de Biossegurança (CTNBio). Instrução normativa 20 de 11 de dezembro de 2001. Diário Oficial da União, Brasília. 17 jan. 2002.

BRASIL.

Ministério da Ciência e Tecnologia. Medida provisória 2.191-9. Acresce e altera dispositivos da lei 8.974, de 5 de janeiro de 1995, e dá outras providências. Diário Oficial da União, Brasília. 24 ago. 2001.

BRASIL.

Decreto 1.752 de 20 de dezembro de 1995.
Dispõe sobre a vinculação, competência e composição da Comissão Técnica Nacional de Biossegurança - CTNBio e dá outras providências. Diário Oficial da União, Brasília. 21 dez. 1995.

BRASIL.

Congresso Nacional. Lei 8.974 de 05 de janeiro de 1995. Estabelece normas para o uso das técnicas de engenharia genética e liberação no meio ambiente de organismos geneticamente modificados. Diário Oficial da União, Brasília. 6 jan. 1995.

BRASIL.

Ministério do Meio Ambiente. Secretaria de Biodiversidade e Florestas. Convenção Sobre Diversidade Biológica. Disponível em: http:// www.mma.gov.br/sitio/index.php?ido=conteudo. monta\&idEstrutura $=72$ \&idMenu $=2335$. Acesso em: 28 jun. 2009. s.d.

CARMO, Aurélio Hipólito do.Organismos geneticamente modificados (OGMs): alimentos, teorias e tendências no Mundo. Tese (Doutorado) - Pontifícia Universidade Católica, São Paulo. 2006.

CARUSO, Denise. Intervention. San Francisco: Hybrid Vigor Press. 2006.

CARVALHO, Thais Dai Ananias de. Uma análise jurídica e bioética da inserção dos organismos geneticamente modificados no Brasil: uma análise sob o ponto de vista dos princípios constitucionais. Dissertação (Mestrado) Universidade Federal de Minas Gerais, Belo Horizonte. 2003. 
CAVALCANTI, Ana Elizabeth Lapa Wanderley. O impacto da rotulagem dos alimentos transgênicos nos direitos da personalidade e na sadia qualidade de vida. Tese (Doutorado) - Pontifícia Universidade Católica, São Paulo. 2006.

CAVALLI, Suzi Barletto.

Segurança alimentar: a abordagem dos alimentos transgênicos. Revista de Nutrição, São Paulo, v.14, p.41-46. 2001.

COSTABILE E SOLIMENE, Roberto Caruso.Rotulagem de alimentos transgênicos: responsabilidade da administração por deficiência na fiscalização. Dissertação (Mestrado) - Pontifícia Universidade Católica de São Paulo, São Paulo. 2004.

DOMINGO, José.

Toxicity studies of genetically modified plants: a review of the published literature. Critical Reviews in Food Science and Nutrition, London, v.47, p.721-733. 2007.

FAGAN, John.

The failings of the principle of substantial equivalence in regulating transgenic foods. NetLink Direkt-Service. Disponível em: http:// www.netlink.de/gen/jfsubeq.htm. Acesso em: 8 jun. 2002. 2002.

FAO.

Food and Agriculture Organization of the United Nations. Joint FAO/WHO Expert Consultation on Foods Derived from Biotechnology. Topic 1: The concept of substantial equivalence, its historical development and current use. Nick Tomlinson, Food Standards Agency. United Kingdom. Disponível em: http://www.who.int/fsf/GMfood /Consultation_May2000/Documents_ list.htm. Acesso em: 7 dez. 2007. 2000.

\section{FDA}

Food and Drug Administration. Guidance for industry: use of antibiotic resistance marker genes in transgenic plants. Center for Food Safety and Applied Nutrition. Draft guidance. Disponível em: http://vm.cfsan.fda.gov/ dms/ opa-armg.html. Acesso em: 10 abr. 2006. 4 set. 1998.

FRANCO, Silvania Bezerra.

A responsabilidade civil na relação de consumo de produtos transgênicos. Dissertação (Mestrado) Universidade Federal do Pará, Belém. 2006.

FREESTONE, David; HEY, Ellen.

Origins and development of the precautionary principle. In: Freestone, David; Hey, Ellen. The precautionary principle and international law. London: Kluwer Law International. 1996.
JEFFREY, M. Smith.

Perigo dos alimentos manipulados geneticamente. In: Zanoni, Magda (Org.). Transgênicos, terapia genética, células-tronco: questões para a ciência e para a sociedade. Brasília: Núcleo de Estudos Agrários e Desenvolvimento Rural, Instituto Interamericano de Cooperação para a Agricultura. p.25-33. (NEAD Debate, 1). 2004.

LACADENA, Juan Ramón.

Plantas y alimentos transgénicos. Madrid: Departamento de Genética, Facultad de Biología, Universidad Complutense. Disponível em: http://cerezo.pntic.mec.es/ jlacaden/ Ptransg0.html. Acesso em: 7 dez. 2007. 1998.

LACEY, Hugh.

A controvérsia sobre os transgênicos: questões científicas e éticas. Aparecida: Ideias \& Letras, 2006.

LACEY, Hugh.

Investigating the environmental risks of transgenics crops. Trans/form/ação, São Paulo, v.27, n.1, p.111-131. 2004.

LEWGOY, Flávio.

A voz dos cientistas críticos. História, Ciências, Saúde - Manguinhos, Rio de Janeiro, v.7, n.2, p.503-508. 2000.

LOSEY, John; RAYOR, Linda; CARTER, Maureen.

Transgenic pollen harms monarch larvae. Nature, v.399, n.6733, p.214-215. Disponível em: http://www.biotech-info.net/transpollen. html. Acesso em: 5 maio 2006. 1999.

MALUF, Renato.

Segurança alimentar e nutricional. Petrópolis: Vozes. 2007.

MARINHO, Carmem Luiza Cabral.

Discurso polissêmico sobre plantas transgênicas no Brasil: estado da arte. Tese (Doutorado) Escola Nacional de Saúde Pública, Fiocruz, Rio de Janeiro. 2003.

MARINHO, Carmem Luiza Cabral; MINAYOGOMEZ, Carlos.

Decisões conflitivas na liberação dos transgênicos no Brasil. São Paulo em Perspectiva, São Paulo, v.18, n.3, p.96-102. 2004.

MENEZES, Francisco; BURLANDY, Luciene; MALUF, Renato.

Princípios e diretrizes de uma política de segurança alimentar e nutricional: textos de referência para a II Conferência Nacional de Segurança Alimentar e Nutricional. Brasília: Conselho Nacional de Segurança Alimentar e Nutricional. 2004. 
MILLSTONE, Erik; BRUNNER Eric; MAYER, Sue. Beyond 'substantial equivalence'. Nature, v.401, p.525-526. 1999.

NODARI, Rubens Onofre; GUERRA, Miguel

Pedro.

Plantas transgênicas e seus produtos: impactos, riscos e segurança alimentar (biossegurança de plantas transgênicas). Revista de Nutrição, São Paulo, v.16, n.1, p.105-116. 2003.

PARLAMENTO EUROPEU.

Diretiva 2001/18/CE de 12 de março de 2001, relativa à libertação deliberada no ambiente de organismos geneticamente modificados. Jornal Oficial, n.L106, p.1-39. 17 abr. 2001.

PAZ, Viviane Candeia.

Alimentos e biossegurança: o caso da soja transgênica. Dissertação (Mestrado) Universidade Regional do Noroeste do Estado do Rio Grande do Sul, Ijuí. 2004.

PINTO, Eduardo Romano Campos. Plantas transgênicas resistentes a viroses: obtenção e estudos de segregação não medeliana. Tese (Doutorado) - Universidade de Brasília, Brasília. 2002.

PIZZATTO, Marilândia Marsaro.

Uma avaliação prospectiva dos efeitos econômicos da adoção de soja transgênica no Brasil.

Dissertação (Mestrado) - Universidade Federal de Mato Grosso do Sul, Campo Grande. 2006.

PUSZTAI, Árpád.

Submission of dr. Árpád Pusztai. Disponível em: http://www.freenetpages.co.uk/hp/a.pusztai/ NewZealand/nz-arpad.htm. Acesso em: 9 jul. 2005. 2002.

RUTTAN, Vernon W.

Biotechnology and agriculture: a skeptical perspective. AgBioForum, v.2, n.1, p.54-60. Disponível em: http://www.agbioforum.org. Acesso em: 7 dez. 2007. 1999.

SALLES, Alessandra Alvissus de Melo. Alimentos transgênicos no Brasil: análise dos reflexos da legalização à luz dos princípios de direito ambiental. Dissertação (Mestrado) Universidade de Taubaté, Taubaté. 2006.
SOUSA, Eduardo Luis Leão de. Preservação da identidade de grãos e a coordenação dos sistemas agroindustriais. Tese (Doutorado) - Universidade de São Paulo, São Paulo. 2001

SOUZA, José Augusto de.

Avaliação da soja transgênica à luz do ambiente institucional. Dissertação (Mestrado) Universidade Estadual do Oeste do Paraná, Cascavel. 2006

SPENDELER, Lilian.

Organismos modificados geneticamente: una nueva amenaza para la seguridad alimentaria. Revista Española de Salud Pública, Madrid, v.79, n.2, p.271-282. 2005.

TOKAR, Brian.

Biohazards: the next generation? - genetically engineering crop plants that manufacture industrial and pharmaceutical proteins. Disponível em: http://www.edmondsinstitute.org. Acesso em: 6 ago. 2007. 2001.

TRAAVIK, Terje; CHING, Lim Li (Ed.). Biosafety first: holistic approaches to risk and uncertainty in genetic engineering and genetically modified organism. Trondheim: Tapir Academic Press. 2007.

UNION OF CONCERNED SCIENTISTS.

Risks of genetic engineering. fact sheet. Disponível em: http://www.ucsusa.org/food/ gen.risks.html. Acesso em: 10 abr. 2006. 2001.

VALLE, Silvio.

Transgênicos sem maniqueísmo. História, Ciências, Saúde - Manguinhos, Rio de Janeiro, v.7, n.2, p.493-98. 2000.

VENZKE, Janaina Guimarães.

Segurança alimentar de milho geneticamente modificado contendo o gene cry Ab de Bacillus thuringiensis. Dissertação (Mestrado) -

Universidade Federal de Pelotas, Pelotas. 2006.

WHO

World Health Organization. Modern food biotechnology, human health and development: an evidence-based study. Disponível em: www.who.int/foodsafety. Acesso em: 5 nov. 2008. 2005. 